\title{
The application of Multiwave method of shallow earthquake of barite ore exploration in Guizhou district
}

\author{
Huiguo Liu \\ Guizhou Vocational Technology Institute, Guiyang, Guizhou 550023, China \\ huiguo_liu@outlook.com
}

Keywords:engineering, seismic prospecting, seismic image, Rayleigh wave, velocity analysis.

\begin{abstract}
Through the analysis of velocity, spectrum of the multiwavemethods of shallow earthquake exploration, this paper makes analysis on the barite ore nearby the downstream river bank of Xialuotuo River in Qianxi County Stone Township of Guizhou province. The research shows that (1) When the wave velocity is more than $4000 \mathrm{~m} / \mathrm{s}$, it is the area of barite ore. (2)During the analysis of surface wave velocity, which is more than $600 \mathrm{~m} / \mathrm{s}$, it is presumed to be ore body reaction.(3)The methods of shallow earthquake exploration is effective to the exploration of barite but the data needs to be corrected.
\end{abstract}

\section{Introduction}

The so-called multiwave method of shallow earthquake refers to be the longitudinal, shear and surface wave, which is a practical use of a kind of method in the engineering exploration according to the features of propagation path of wave, such as incident wave, reflected wave, direct wave, refraction, transmission and sliding wave or the direction of particle vibration[1]. For a long time, in the exploration of shallow earthquake, people mainly study the propagation rules of seismic wave motivated by human in the medium of rock and soil to explore the structure of shallow strata or measure the characteristics of mechanical parameters of rock and soil.Therefore, it is widely applied in the fields like the engineering geological exploration,construction site evaluation, road, railway,water conservancy and hydropower and archaeology[2-5]. But, the exploration of shallow earthquake is not much used for the mineral exploration. Even though in the Technical Specification of Shallow Earthquake Exploration Dz/T0170-1997of ministry of geology and mineral resources, it refers to energy resource, mineral geological survey and other explorations of a variety of metals and nonmetal mineral deposits. The relevant material show that shallow earthquake exploration method is less used for the mineral exploration in Guizhou district. This paper introduces the situation of barite ore exploration based on the method of shallow earthquake exploration used in Qianxi and Yanhe County of Guizhou province to attract the attention of colleagues of the industry and make it widely used.

\section{The general situation of mine and the objective of exploration}

The mine is located in nearby the downstream river bank of Xialuotuo River in Qianxi County Stone Township of Guizhou province, whose altitude is $963 \mathrm{~m}$ with the geographic coordinates of latitude $26^{\circ} 54^{\prime} 21^{\prime \prime} \mathrm{N}$ and longitude $106^{\circ} 21^{\prime} 06^{\prime \prime} \mathrm{E}$. Barite has the shape of vein and is produced in dolomite of Triassic Yelang group (Tly). Controlled by the fault of north east trending, barite is white and dense with high content of $\mathrm{BaSO}_{4}$. Its item evaluation grade can reach more than $95 \%$. There are two parallel ores trending from north east to south west with the distance of about $20 \mathrm{~m}$ in this mine. The height of main pulse is $1.5 \mathrm{~m}$ with the tendency of $135^{\circ}$ and inclination of $45 \sim 50^{\circ}$ of which the north east area has been explored and south west has been covered by the hidden layer. The trending of the mineral ore is north east of $45^{\circ}$ ans is output from the parallel bedding with the length of surface outcrop of about $40 \mathrm{~m}$. This paper aims to investigate the overall length and the extension of tilt direction and intends to use the seismic image of shallow earthquake and surface wave to wxplore it. 


\section{The genesis of ore deposit, its geological structure and geophysical prerequisite}

Generally speaking, the causes of formation of China's barite ore deposit is divided to five types like sedimentary type, stratabound ore type, vein hydrothermal type, volcano sedimentary type and residual type according to the mineralization mechanism of the deposit, formation and the relation between core body and surrounding rock. There are two main types in Guizhou province:1. The type of vein of stratabound barite deposit. It is produced in dolomite of Triassic Yelang group. In the favorable structure position, barite ore has the form of vein and trending along the fault strike or rock bedding with the minority of that cut bedding. So, the geological condition of lithology and structure in ore bearing strata is closely related to each other. 2. The residual slope deposit type: it is produced in the residual and accumulated sub- clay of quaternary (Q) and is distributed with the forms of mass and lens. Topography:the low mound or flat areas ans the thickness of clay rock is more than $10 \mathrm{~m}$. There are three groups of Yelang group layer and structure distribution, or it is difficult to form residual slope barite ire.Geophysical features: Compared with the cover and surrounding rock, barite ore deposit has the features of high density and velocity and strong amplitude and through the velocity scanning and frequency analysis, it can also reflects obvious anomalies[6]. So, based on this, looking for the features of fault zone, anomalies of high velocity and frequency is the important basis of this exploration.

\section{The instrument for measuring line layout and field data collection}

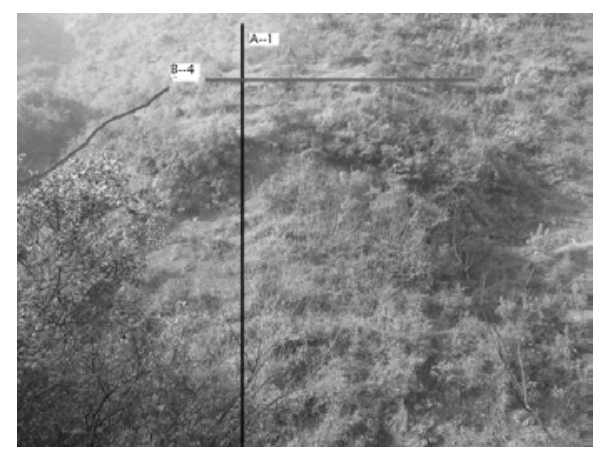

Fig. 1 the picture of line layout

1). Measuring it according to the line of intended section of position(Fig. 1). 2). Measuring the profile position: referring to the pile position number of field measurement and calibration and after that, it is the measured profile position. 3). for the (vertical and horizontal)line explored, the research adopts the equal dot pitch and offset(namely: dot pitch is $0.5 \sim 1.0 \mathrm{~m}$ and the offset is $4 \sim 20 \mathrm{~m}$ ) to make continuous survey along the section.4). Seismic image receiver is high damping detector of $38 \mathrm{~Hz}$ and the sampling interval is $200 \sim 500 \mu \mathrm{s}$. Rayleigh wave test uses $4.5 \mathrm{~Hz}$ detector with the channel spacing of $2 \mathrm{~m}$ and offset of $2 \sim 20 \mathrm{~m}$. 5). In the area of undulation terrain elevation, the research adopts the low end excitation and high end reception(namely:hammer point is in the low land and the receiver is in the high land). 6). the installation of receiver: making it completely contact with dense soil and install it firmly with the hammering force perpendicular to the ground. 7).The instrument of this survey is seismograph DZQ24c produced by geological instrument factor in Chongqing, which uses vibration hammer and receives waves by pass band.

\section{Data processing and material analysis}

\section{1). Data processing:}

The data processing of seismic image adopts the system of shallow earthquake data processing of CSP6.0 of the professional software of Geogiga Corporation in Canada and the physical and chemical research center of Beijing Institute of Geology in nuclear industry. The processing content is velocity scanning, spectrum analysis,parameters filtering, filtering, differential, equilibrium and terrain correction. The result of processing is time section for inference explanation, that is the section of seismic image result. The processing of rayleigh wave: it divides and determines bedrock depth 
according to the curve inflection point and wave velocity of the spectrum curve gained by Geogiga software.

2). Material explanation

A. Fault zone: Taking the time section ofB4-B4 as an example, in this section, the paths of $7 \sim 16$ and $93 \sim 100$ are roughly in the depth of $30 \mu$ s. The same direction of axis is obviously wrong and the amplitude and frequency change obviously (Fig.2,a).B4-B4 times section. The above picture is the uncorrected landscape (Fig.2,a) and the following picture is the corrected landscape (Fig.2,b).

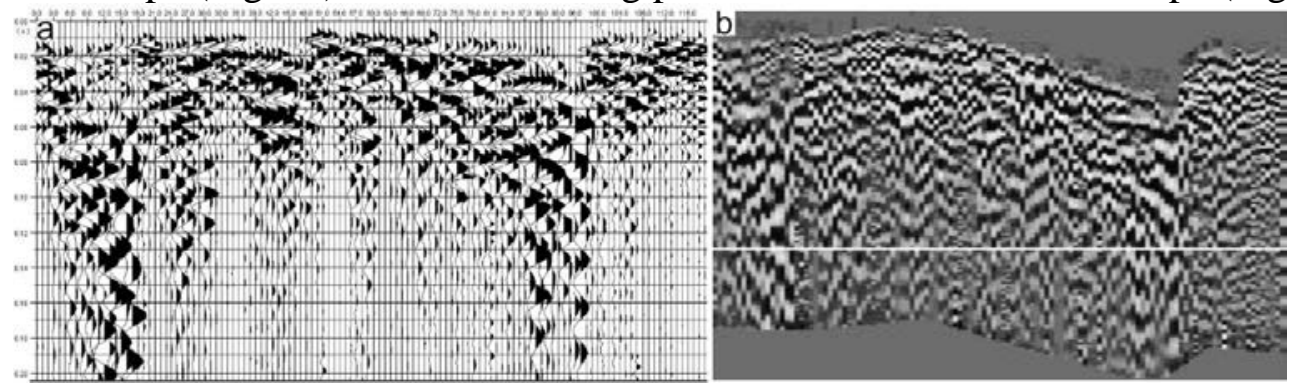

Fig.2 B4-B4` section a. Time section b. The correction of section landscape

B. The anomaly of high frequency and velocity: In the fault zone, the frequency is lower obviously and at a minimum figure with the frequency higher than the area of $80 \mathrm{~Hz}$. It is inferred to be the area of barite ore occurrence(Fig.3,a)with the path of $70 \sim 75$, time window of $12 \times 20 \mathrm{~ms}$, similarity $>0.9$, equal time depth of $40 \mathrm{~ms}$ and velocity of $4000 \mathrm{~m} / \mathrm{s}$ (Fig.3,b).Taking $90 \sim 100$ path, the time window of $12 \times 20 \mathrm{~ms}$, similarity $>0.9$, equal time depth of $40 \mathrm{~ms}$ and velocity of $3500 \mathrm{~m} / \mathrm{s}$. When the velocity is higher than $4000 \mathrm{~m} / \mathrm{s}$, it is inferred to be the area of barite ore occurrence (Fig 3,c)..

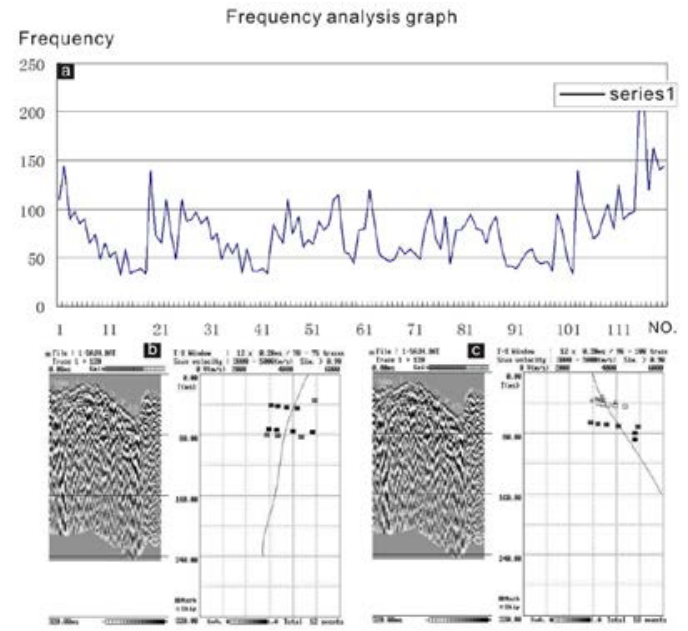

Fig. 3 cross section a. B-B4 spectrum analysis curve;b. B-B4section70 75 path, time and depth conversion;c. B-B4section 90 100 path, time and depth conversion
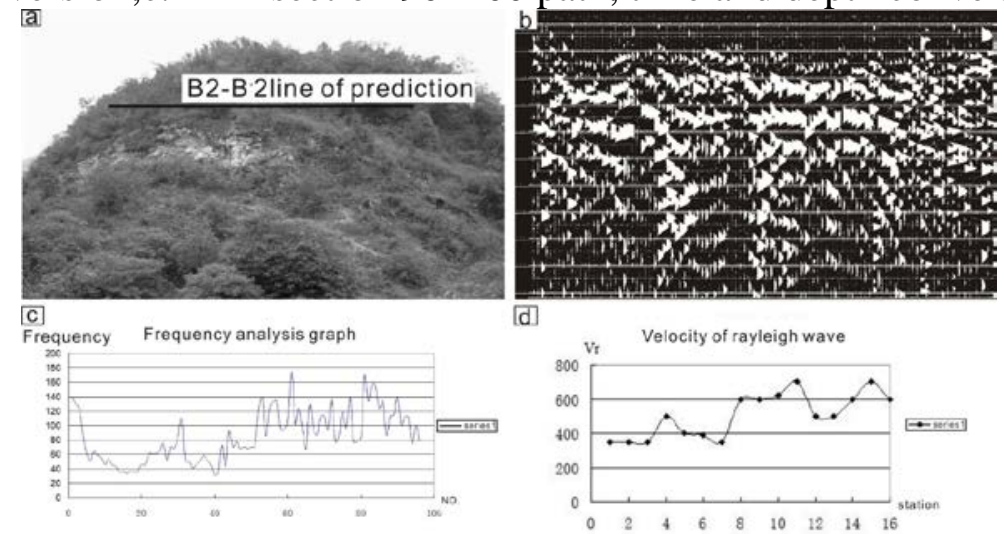

Fig. 4 B2-B2 the comprehensive analysis of cross section; a. Top line position; b. Seismic image time; c. Spectrum analysis curve; d. Rayleigh wave velocity curve

The following picture is the line of seismic image and surface wave distributed on the exposed section of mine (Fig 4, a). The time section of seismic image is as follows(Fig 4,b).The analysis on the 
spectrum and surface wave velocity in the exposed section of ore and in the analysis on the spectrum , the area higher than $110 \mathrm{~Hz}$ is inferred to be reflection of ore(Fig 4,c). In the analysis on the surface wave velocity, the area higher than $60 \mathrm{~m} / \mathrm{s}$ is inferred to be reflection of ore (Fig 4, d).

\section{The survey results and mining verification}

This survey completes about 800points of physical test point with more than 580m of the line and gains three seismic image time sections: one meets reflection wave line and ensures the fault zones of two sections and in the same time, the survey accomplishes the 13 sites of surface wave. After the comparative analysis, it concludes the distribution map of geophysical anomaly. Compared with the wall rock, barite ore deposit has the features of high density and velocity and strong amplitude. In time section, the analysis on the velocity scanning and spectrum, there are a few groups of anomalies, of which the high velocity and frequency anomaly generally reflect the distribution trend of underground barite ore. Due to limited workload, the data gained in this survey only reflects the local conditions and fails to make comprehensive explanation and evaluation. In the work, the focus in on the distribution of plane anomaly and fails to conduct detailed research on the buried depth of ore body. But the anomaly reflected in the scoped of the work can be considered to be the reflection of ore body. This conclusion is verified by the later exploration. In the areas of high velocity and frequency anomaly, we can see the mine to different degrees while in the non-abnormal area, we do not see a large or small scale of ore body. The survey about the mine along the river is generally same as the Qianxi mine site and the difference is that the Qianxi mining is open excavation by excavator whereas the river mining is the tunnel excavation. Due to deep bury along the river, there are discrepancies in the anomaly provided by the seismic exploration, the general correct of plane position and the depth, which is due to that the velocity is not accurate enough when adopting time and depth conversion and also due to the insufficient work. The above two barite ores, which use the shallow earthquake exploration show that this method is feasible.

\section{References}

[1]Shan N L. Engineering Seismic Exploration (in Chinese)[M]. Beijing: Metallurgical Industry Press, 2006.

[2]Wang Z D. Applied Technology fo Shallows Seismic Prospecting (in Chinese)[M]. Beijing:Geological Publishing House,1988

[3]Jiang H Y. Seismic exploration of rock composition and properties[M]. Beijing: Petroleum Industry Press,1986

[4] Wang Q H,Xu M C. Anti-interference hogh resolution shallow seismic prospecting(in Chinese)[M] . Beijing:Geological Publishing House,1991

[5] Yao Y. Seismic Waves and Seismic Exploration (in Chinese)[M]. Beijing: Geological Publishing House, 2006

[6] Zhong S H,Sun H Z,Wang R. Landsonar.(in Chinese) [M]. Beijing: China Science and Technology Press.2012 